\title{
Repasse de ICMS ecológico em Santarém (2014-2018) baseado nas taxas de desmatamento municipal
}

Em função das altas taxas de desmatamento registradas nesses municípios, deveriam eles receber menor volume de repasses financeiros sob a nova sistemática de repartição de receitas, considerada a dupla função do ICMS Ecológico e o objetivo assumido na experiência paraense de combate ao desmatamento por meio do fomento à participação dos entes municipais. Desse modo, nota-se que o ICMS Verde tem duas dimensões: uma compensatória, como forma de corrigir o desequilíbrio de oportunidades de desenvolvimento econômico entre os municípios, decorrente de restrições de natureza ambiental; e outra, incentivadora, sob a qual se busca induzir os entes municipais a se adequar aos critérios de repartição de receitas definidos pela política. $O$ banco de dados utilizado nesse trabalho foi estruturado através de pesquisa no sistema de informações da Secretaria de Estado de Meio Ambiente e Sustentabilidade-SEMAS, do Estado do Pará, que disponibiliza tais dados para consulta do público interessado no assunto, de forma online no site do órgão. A taxa de desmatamento municipal diminuiu entre os anos de 2012 a 2014, mostrando que neste período este fator, atrelado ao aumento percentual no valor do repasse do ICMS Ecológico, colaborou para que a cidade subisse algumas posições no ranking estadual. Já no ano de 2015 , houve um aumento nas taxas de desmatamento municipal, devido ao grande número de incêndios ocorridos na região, que associado a menor ocorrência de chuvas, favorecido pelo fenômeno do El Niño, colaborou na queda de Santarém, dentro do ranking de repasse do referido imposto. No ano de 2016, houve uma redução na taxa de desmatamento, ocasionando a ascensão para a 13 a posição no ranking estadual, refletindo no maior repasse do valor do ICMS ecológico ao município.

\section{Transfer of ecological ICMS in Santarém (2014-2018) based on municipal deforestation rates}

\begin{abstract}
Due to the high rates of deforestation recorded in these municipalities, they should receive less volume of financial transfers under the new system of revenue sharing, considering the double function of the Ecological ICMS and the objective assumed in the Pará experience of fighting deforestation through fostering the participation of municipal entities. Thus, it is noted that the Green ICMS has two dimensions: a compensatory one, as a way of correcting the imbalance of economic development opportunities between the municipalities, due to environmental restrictions; and another, encouraging, under which it seeks to induce municipal entities to adapt to the revenue sharing criteria defined by the policy. The database used in this work was structured through research in the information system of the State Secretariat of Environment and Sustainability-SEMAS, of the State of Pará, which makes such data available for consultation by the public interested in the subject, online on the website of the organ. The rate of municipal deforestation decreased between the years 2012 to 2014 , showing that in this period this factor, linked to the percentage increase in the value of the transfer of ICMS Ecológico, helped the city to rise some positions in the state ranking. In 2015, there was an increase in municipal deforestation rates, due to the large number of fires that occurred in the region, which associated with less rainfall, favored by the $\mathrm{El}$ Niño phenomenon, contributed to the fall of Santarém, within the ranking of transfer of said tax. In 2016, there was a reduction in the rate of deforestation, causing the rise to 13 th position in the state ranking, reflecting the greater transfer of the value of ecological ICMS to the municipality.
\end{abstract}

Keywords: Amazon; Economy; Sustainability.

Topic: Desenvolvimento, Sustentabilidade e Meio Ambiente

Reviewed anonymously in the process of blind peer.

Mauricio Dumont Ferreira Sousa (iD)

Universidade Federal do Oeste do Pará, Brasil

http://lattes.cnpq.br/9400701028122864

http://orcid.org/0000-0003-3143-5413

dumont.eng.f@gmail.com

Mayra Piloni Maestri (iD

Universidade Federal Rural da Amazônia, Brasil

http://lattes.cnpq.br/2687102042811310

http://orcid.org/0000-0002-8936-952X

mayrapmaestri@hotmail.com

Marina Gabriela Cardoso de Aquino (D)

Universidade do Estado de Santa Catarina, Brasil

http://lattes.cnpq.br/2168843028631934

http://orcid.org/0000-0002-0160-0804

marinaacardosoo@gmail.com

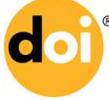

DOI: 10.6008/CBPC2318-2881.2020.003.0010
Received: 05/05/2020

Approved: 30/06/2020

Lívia Karine Lima Rabelo (iD

Universidade Federal do Oeste do Pará, Brasil

http://lattes.cnpq.br/2513116920954057

http://orcid.org/0000-0002-7294-6423

liviarabello16@gmail.com

Ana Kaira Canté da Conceição (iD

Universidade Federal do Oeste do Pará, Brasil

http://lattes.cnpq.br/0359544394358895

http://orcid.org/0000-0003-2288-1622

anakaira17@gmail.com

\section{Referencing this:}

SOUSA, M. D. F.; MAESTRI, M. P.; AQUINO, M. G. C.; RABELO, L. K. L.; CONCEIÇÃO, A. K. C.. Repasse de ICMS ecológico em Santarém (20142018) baseado nas taxas de desmatamento municipal. Nature and Conservation, v.13, n.3, p.106-111, 2020. DOI: http://doi.org/10.6008/CBPC2318-2881.2020.003.0010 


\section{INTRODUÇÃO}

O Imposto sobre Circulação de Mercadorias e Serviços (ICMS) é um valor acrescido aos bens e serviços de caráter estadual, do qual incide sobre operações que estejam relacionadas à circulação de mercadorias e prestações de serviços de transporte e comunicação. Possuindo como finalidade ressarcir os cofres públicos para que os estados possam custear suas despesas com os serviços públicos e funções constitucionalmente instituídas (ROSSI et al., 2011).

Segundo Fernandes et al. (2011), o art. 158 da Constituição Federal de 1988 estipulou que os estados definissem, com legislação específicas, parte dos critérios para o repasse do ICMS a que os municípios têm direito. No mesmo artigo, ficou determinado que $75 \%$ do valor repassado seja apropriado pelo estado, sendo os $25 \%$ restante destinados aos municípios. Dentro deste, cerca de $18,75 \%$ são divididos de acordo com a Legislação Federal, tendo como critério a contribuição municipal do imposto arrecadado pelo estado e o restante, 6,25\%, são divididos de acordo com a legislação de cada estado (SOUZA JUNIOR, 2016).

Conforme o mesmo autor, o ICMS Ecológico nasceu como mecanismo tributário, que possibilitou aos municípios o repasse de parcelas maiores que aquela que se tinha direito, desde que o município atendesse a critérios ambientais estabelecidos em legislação estadual. Enfatiza ainda que este funciona como novo critério para a redistribuição dos recursos advindos do ICMS de acordo com o nível de atividade econômica que os municípios mantêm, em conjunto com a preservação e conservação do meio ambiente sustentável, daí parte a denominação de ecológico. Logo, aqueles municípios que preservam ou conservam suas florestas e a biodiversidade ganham pontuações maiores nos critérios de repasse dos recursos, atuando como forma de incentivo e compensação.

Conforme Gonçalves et al. (2017), no ano de 2012 normatizou-se o ICMS Ecológico no Pará, lei estadual $n^{\circ} 7.638 / 2012$, trazendo consigo um novo mecanismo para a distribuição das receitas públicas, preservação ambiental, justiça fiscal e melhorias na qualidade de vida da população local. O valor do imposto repassado se baseia em critérios peculiares ao estado, inicialmente sendo a quantificação das áreas protegidas e de uso especial, estoque da cobertura vegetal e área desmatada e área municipal inserida no Cadastro Ambiental Rural (MERLIN et al., 2016). Posteriormente, conforme lei estadual $n^{\circ} 7.638 / 2012$ e regulamentada pelo decreto estadual $n^{\circ} 1.696 / 2017$, passou-se a adotar quatro fatores para avaliar o esforço ambiental dos municípios paraenses, sendo a regularização ambiental dos produtores rurais através do CAR, impacto territorial das áreas protegidas e a gestão sobre as unidades de conservação, estoque florestal e fortalecimento da gestão ambiental do município (GONÇALVES et al., 2017).

O município de Santarém, por sua vez, localiza-se entre os rios Tapajós e Amazonas, possui cerca de 300 mil habitantes, sendo cortada pela BR-163 e, mais ao sul, a aproximadamente 200 km do município, se cruza com a BR-230 conhecida como transamazônica, rodovias consideradas os principais eixos de desmatamento no estado. Esses conjuntos de condições citadas anteriormente fazem com que Santarém seja uma região de grande pressão para abertura de áreas e, atrelado a isso, encontra-se o fato de que a cidade foi anteriormente atingida por vários incêndios em assentamentos, unidades de conservação e terras 
indígenas, o que gera impactos diretos no repasse do ICMS Ecológico (PEGURIER et al., 2016).

Vale ressaltar que o ICMS Ecológico não é um novo imposto; ele apenas adotou novos critérios para a distribuição do imposto que é arrecadado, a principal finalidade do mesmo foi criar uma forma saudável de competição por recursos entre os municípios onde aquele que mais protege, conserva e investe na conservação ambiental, na saúde e na educação recebe maior parcela do imposto; ou seja, o ICMS Ecológico visa estimular a adoção de medidas que conservem o meio ambiente e promovam o bem-estar socioeconômico (SILVA JÚNIOR et al., 2013). Nesse sentido, o objetivo do trabalho foi analisar e demonstrar o repasse do ICMS Ecológico no município de Santarém, Estado do Pará.

\section{MATERIAIS E MÉTODOS}

O Estado do Pará é o segundo maior da região Norte, tendo um território de $1.253 .164,5$ km², sendo conhecido como a porta de entrada da Amazônia (IBGE, 2018). No entanto, hoje em dia, é um dos recordistas em desmatamento florestal e sofre incessantemente os problemas deixados pelas diversas políticas de desenvolvimento malogradas (SEMAS, 2019).

O município de Santarém ocupa uma área de $22.887,080 \mathrm{~km}^{2}$ e é o principal centro urbano financeiro, comercial e cultural do oeste do estado do Pará, sendo uma das cidades mais antigas da região amazônica e se constituiu como uma das mais importantes também, pois é o 3o município mais populoso do Pará, o 70 de toda a região norte e o 83 do Brasil e briga mais de 294 mil pessoas, de acordo com o senso feito pelo Instituto Brasileiro de Geografia e Estatística (IBGE) em 2016.

Segundo dados de 2014, possui um Produto Interno Bruto (PIB) de $R \$ 3,7$ bilhões, ligado principalmente ao setor de serviços e comércio, mas também ao extrativismo e à indústria, é o sétimo município com maior PIB do estado (PREFEITURA DE SANTARÉM, 2020). O banco de dados utilizado nesse trabalho foi estruturado através de pesquisa no sistema de informações da Secretaria de Estado de Meio Ambiente e Sustentabilidade-SEMAS, do Estado do Pará, que disponibiliza tais dados para consulta do público interessado no assunto, de forma online no site do órgão (SEMAS, 2019).

Foram tabulados os dados de contribuição do município de Santarém, no Estado do Pará entre os anos de 2014 a 2018, no programa Microsoft Excel 2016. Para discussão dos dados foram utilizados dados do Projeto PRODES, que faz o monitoramento do desmatamento através de satélites, que assim como a SEMAS, disponibilizam estes dados para consulta pública.

\section{RESULTADOS E DISCUSSÃO}

Segundo a Secretaria de Meio Ambiente e Sustentabilidade - SEMAS (2019), o ICMS Ecológico, em 2014 representava apenas 2\% do valor total redistribuído aos municípios, em 2015 o valor repassado foi referente a 4\%, em 2016 houve um salto para 6\% e, finalmente, no ano de 2017 o repasse foi referente a $8 \%$ do valor repassado, e assim ficou estipulado para repasses futuros.

De acordo com os dados obtidos, no ano de 2014 o valor do ICMS Ecológico transferido ao município de Santarém foi de R\$̣ $347.224,43$, obtendo a 32으 posição no ranking do repasse deste imposto no Pará 
(SEMAS, 2019), como visto na tabela 1. Uma vez que, em 2012 foi observado 18,3 $\mathrm{km}^{2}$ de área total desmatada no município, abaixo da taxa de desmatamento dos municípios prioritários no combate ao desmatamento, que é de até $40 \mathrm{~km}^{2}$ ao ano (IMAZON, 2018).

Tabela 1: Quadro do repasse do ICMS Ecológico em Santarém - PA, baseado nas taxas de desmatamento municipal.

\begin{tabular}{lllll}
\hline Ano do Repasse & Ano Base do Repasse & $\begin{array}{l}\text { Área Desmatada } \\
\left(\mathrm{km}^{2)}\right.\end{array}$ & $\begin{array}{l}\text { Valor Repassado } \\
(\mathrm{R} \$)\end{array}$ & Posição no Ranking Estadual \\
\hline 2014 & 2012 & 18,3 & $347.224,43$ & 32 o \\
2015 & 2013 & 9,8 & $739.348,93$ & 310 \\
2016 & 2014 & 17,2 & $1.159 .803,82$ & 28 o \\
2017 & 2015 & 54,3 & $1.470 .890,84$ & 31 o \\
2018 & 2016 & 16,9 & $1.729 .951,62$ & 13 은 \\
\hline
\end{tabular}

Já no ano de 2015 como observado na Tabela 01, foi repassado R\$ 739.348,93, ficando o estado em 310 colocado no ranking estadual (SEMAS, 2019). No ano de 2013 , houve $9,8 \mathrm{~km}^{2}$ de áreas desmatadas, comprovando que houve diminuição nas taxas de desmatamento, se comparado ao ano anterior, o que colaborou para que o município desse este salto quanto ao valor repassado. Este fato também pode ser explicado pelo aumento na porcentagem de repasse aos municípios, conforme normatiza a lei no 7.638/2012 referentes ao ICMS Ecológico. Os valores e critérios legalmente constituídos passam então a ser quantificados diante dos dados fáticos, propiciando a definição de um ranking ecológico dos municípios, ou seja, cada município receberá um valor proporcional ao compromisso ambiental por ele assumido, o qual pode ser maximizado conforme a melhoria da qualidade de vida da população (DERANI, 2004). Ainda segundo este autor um dos pontos principais da política é, portanto, a não criação de novo tributo, não subsistindo qualquer ônus financeiro para o Estado ou aumento da carga tributária dos contribuintes, pois constitui-se unicamente da adoção de critérios ambientalmente relevantes para a repartição das receitas normalmente obtidas (DERANI, 2004).

No ano de 2016 foram repassados $\mathrm{R} \$ 1.159 .803,82$ ao município, Ihe concedendo a 29o posição dentro do panorama de repasse do ICMS Ecológico no Estado do Pará (SEMAS, 2019), no ano referente, a área desmatada no município foi de $17,2 \mathrm{~km}^{2}$, mostrando que houve aumento do valor transferido ao município em relação ao ano anterior.

Assim, é possível observar que os municípios que se dedicam ao desenvolvimento econômico em detrimento da preservação ambiental acabam acumulando maior quantidade de repasses financeiros, pois têm mais possibilidade de gerar receitas em função da circulação de mercadorias. Todavia, aqueles que assumem a responsabilidade de preservar o bem natural, trazendo externalidades positivas que beneficiam a todos, têm restrições em sua capacidade de desenvolvimento econômico, recebendo menos repasses financeiros por contarem com uma menor circulação de mercadorias e serviços (DERANI, 2004). Estes afirmam ainda que esta lógica necessariamente deve ser alterada, pois não dá conta da dinâmica da realidade e, principalmente, não se conforma com a proteção constitucional conferida ao meio ambiente.

Loureiro (2002), em seu estudo no Estado do Paraná, concluiu que o ICMS Ecológico contribuiu para a melhoria da conservação da biodiversidade e é maior quando o ICMS Ecológico é combinado com outros instrumentos de política pública ou resulta de parcerias com órgãos federados, principalmente com os 
próprios municípios beneficiados. Além disso, o autor observou que implementar o ICMS Ecológico, por meio de mecanismos participativos é uma oportunidade para que as pessoas se atentem para a cidadania.

No ano de 2017 foram repassados ao município de Santarém R\$1.470.890,84 (SEMAS, 2019). Sendo que em 2015 foi desmatada uma área florestal equivalente a $54,3 \mathrm{~km}^{2}$, o maior foco apresentado durante o período analisado. Além disso, neste ano houve um grande número de incêndios na região, fato que pode ser explicado devido a menor ocorrência de chuvas e ao fenômeno do El Niño, favorecendo a situação (PEGURIER et al., 2016). Tais fatos culminaram com a queda do município para 31a posição no repasse do referido imposto. No ano de 2018, o município de Santarém subiu para a 13a posição no ranking de repasse do ICMS no Pará, sendo repassado o valor de R\$ 1.729.951,62. Essa ascensão explica-se pelo fato de que a área desmatada no ano de 2016 foi de 16,9 km², menos da metade do que no ano anterior.

\section{CONCLUSÕES}

A taxa de desmatamento municipal diminuiu entre os anos de 2012 a 2014, mostrando que neste período este fator, atrelado ao aumento percentual no valor do repasse do ICMS Ecológico, colaborou para que a cidade subisse algumas posições no ranking estadual. Já no ano de 2015 , houve um aumento nas taxas de desmatamento municipal, devido ao grande número de incêndios ocorridos na região, que associado a menor ocorrência de chuvas, favorecido pelo fenômeno do El Niño, colaborou na queda de Santarém, dentro do ranking de repasse do referido imposto. No ano de 2016, houve uma redução na taxa de desmatamento, ocasionando a ascensão para a 13a posição no ranking estadual, refletindo no maior repasse do valor do ICMS ecológico ao município.

Portanto, pode-se inferir que, quanto ao desmatamento o município de Santarém encontra-se em condição favorável de diminuição destas taxas, exceto em 2015, que devido a fatores ambientais, culminou em um aumento da área desmatada. Porém, a posição municipal dentro do ranking estadual, nos remete que a situação ambiental dentro do município precisa da adoção de medidas mitigadoras, que visem proporcionar melhorias na gestão ambiental, para que assim o município possa subir na colocação de recebimento do ICMS Ecológico, que refletirá na proporção de benefícios econômicos, ambientais e sociais a seus habitantes. Faz-se necessário que outros estudos sejam realizados, visando avaliar as outras variáveis embasadas para o cálculo do valor repassado por este imposto, subsidiando práticas para melhoria da gestão ambiental municipal. O ICMS Ecológico do Estado do Pará conforma o recebimento da repartição constitucional da receita do ICMS aos municípios a partir do critério ecológico, que significa a necessidade de cumprimento de objetivos com a finalidade de proteção da floresta amazônica localizada em seu território.

\section{REFERÊNCIAS}

DERANI, C.. Hileia: Revista de Direito Ambiental da Amazônia. Manaus: Universidade do Estado do Amazonas, 2004.

FERNANDES, L. L.; COELHO, A. B.; FERNANDES, E. A.; LIMA, J.

E.. Compensação e incentivo à proteção ambiental: o caso do ICMS ecológico em Minas Gerais. Revista de Economia e Sociologia Rural, v.49, p.521-544, 2011.

GONÇALVES, M. P.; TUPIASSU, L.. ICMS Ecológico como instrumento de política pública ambiental no estado do 
Pará. Revista de Direito Ambiental e Socioambientalismo,

v.3, p.188-202, 2017.

IMAZON. Instituto do Homem e Meio Ambiente da Amazônia. Santarém. Belém: IMAZON, 2018.

LOUREIRO, W.. Contribuição do ICMS Ecológico à Conservação da Biodiversidade no Estado do Paraná. Tese (Doutorado em Engenharia Florestal) - Universidade Federal do Paraná, Curitiba, 2002.

MERLIN, L. V. C. T.; OLIVEIRA, A. C.. ICMS Verde para a redução do desmatamento amazônico: estudo sobre uma experiência recente. Veredas do Direito: Direito Ambiental e Desenvolvimento Sustentável, n.13, p.277-306, 2016.

MOURA, A.. Imposto sobre Circulação de Mercadorias e Serviços Socioambiental: incentivos institucionais e legislação ambiental no Brasil. Revista de Administração Pública, v.49, p.165-188, 2015.

PEGURIER, E. E.; VIEIRA, P. A.. Incêndios na região de Santarém em 2015 superam desmatamento em toda a Amazônia. OECO, 2016.
PREFEITURA DE SANTARÉM. Santarém. 2020.

ROSSI, A.; MARTINEZ, A. L.; NOSSA, V.. ICMS Ecológico sob o enfoque da tributação verde como meio da sustentabilidade econômica: experiência do Paraná. Revista de Gestão Social e Ambiental, v.5, p.90-101, 2011.

SEMAS. Secretaria de Estado de Meio Ambiente e Sustentabilidade. Semas divulga valores monetários do ICMS Verde repassados aos municípios. SEMAS, 2019.

SILVA JÚNIOR, L. H.; PEDROSA, B. M. J.; SILVA, M. F.. Avaliação dos impactos do ICMS Socioambiental na criação de Unidades de Conservação e Unidades de Tratamento de Resíduos Sólidos em Pernambuco: Uma análise a partir do Método de Diferenças em-Diferenças. Revista Econômica do Nordeste, v.44, p.557-572, 2013.

SOUZA JUNIOR, P. R.. A utilização do ICMS-Verde ou Ecológico como Eixo Fundamental da Política Ambiental do Município de Nova Iguaçu/RJ. Revista de Direito Tributário e Financeiro, v.2, p.198-217, 2016.

A CBPC - Companhia Brasileira de Produção Científica (CNPJ: 11.221.422/0001-03) detém os direitos materiais desta publicação. Os direitos referem-se à publicação do trabalho em qualquer parte do mundo, incluindo os direitos às renovações, expansões e disseminações da contribuição, bem como outros direitos subsidiários. Todos os trabalhos publicados eletronicamente poderão posteriormente ser publicados em coletâneas impressas sob coordenação da Sustenere Publishing, da Companhia Brasileira de Produção Científica e seus parceiros autorizados. Os (as) autores (as) preservam os direitos autorais, mas não têm permissão para a publicação da contribuição em outro meio, impresso ou digital, em português ou em tradução. 